Germany, Rewohlt Verlag established a paperback series called "New Women" and, from 1977 to 1995, introduced many women writers' texts, not only from German-language communities but also other nations. In the 1980s, the largest publisher in Germany, Suhrkamp, asked HijiyaKirschnereit to become the editor of a 32-volume series on Japanese literature. This meant rapidly increasing interest in Japanese literature in Germany in the 1980s. In 1990, at the world-famous Frankfurt Book Fair, Japan was selected as the country of theme.

Along with Hijiya-Kirschnereit's translation projects came changes in the book market, general readership, and studies of Japanese women's literature in the German-language community. As discussed above, Hijiya-Kirschnereit's focus is on publications and studies on women's literature in German- and Japanese-language communities. Her 2018 volume reviewed here complements Joan E. Ericson's careful analysis in her Be a Woman: Hayashi Fumiko and Modern Japanese Women's Literature (University of Hawai'i Press, 1997), which pointed out that the literary category joryū bungaku associated sentimentality, lyricism, and impressionism with works of literature written by women, erasing individual differences in women and in each work of literature by the same author. Read in conjunction with Ericson's analysis, Hijiya-Kirschnereit's volume helps us understand the personal and literary history of individual authors, the development of the publishing industry, general and academic readership, and studies of modern Japanese women's literature in the Japanese-, German-, and English-language communities.

\title{
Japanese Kanji Power: A Workbook for Mastering Japanese Characters
}

By John Millen. Tokyo: Tuttle Publishing, 2010. xiii, 304pp. $\$ 26.95$.

\section{Reviewed by Karen Curtin}

Japanese Kanji Power: A Workbook for Mastering Japanese Characters (hereafter, $J K P$ ) boasts 464 kanji in one book, including all kanji on the Advanced Placement (AP) exam in Japanese language, in levels 4 and 5 of the Japanese Language Proficiency Test (JLPT), and taught in Japanese school Grades 1 and 2. It should be noted that since the workbook was

Japanese Language and Literature $\mid$ jll.pitt.edu

Vol. 54 | Number 1 | April 2020 | DOI: https://doi.org/10.5195/j11.2020.147 
published in 2010, it is possible that the kanji covered in these areas have been changed. Further, at the time of publication the JLPT had just been reformed and information about which kanji belonged in the upper levels of 2 and 3 was unavailable; this resulted in the author labeling all possible kanji for level 2 or level 3 as "JLPT 2/3." As well as kanji readings, meanings, and examples, the book contains writing practice and review exercises to help the learner memorize the characters. The book's stated goals for its users are to be able to read and write the kanji characters in words or phrases in which they most commonly appear, with focus on practical vocabulary. The readings listed are those designated by the Japanese Ministry of Education for the Joyō kanji (Common use kanji), hence obscure or lesser used readings are omitted.

$J K P$ is divided broadly into three parts, each of which contains between 108 to 180 kanji characters. These parts are further sub-divided into sets, which in themselves contain approximately twelve kanji each. The author does not state the criteria for this organization. It appears that the order of appearance is based on kanji that have less strokes or are more common, such as words like \#31 水 “water," (17) while later kanji have more strokes or are less common in comparison to earlier characters introduced, such as \#342 決 “decide" (194). The front index table contains a comprehensive list of all the characters organized by sets and showing the character number by order of appearance and associated page number. The back matter has two indexes - one allows the user to look up a character by on-yomi (Chinese reading) and kun-yomi (Japanese reading) and the other lists the characters by number of strokes, although not categorized by radical.

Each introduction of a kanji character includes the kanji number in the workbook, the kanji itself presented in bold brush type, various readings, and a bit of etymologic history or other information to help the reader remember the kanji. The on-yomi is written in both katakana and uppercase Romanization while the kun-yomi is in hiragana and lower-case Romanization. For okurigana (hiragana appearing as part of the word) a nakaguroten $(\cdot)$ separates the kanji reading and the okurigana, whereas parentheses are used to delineate this separation in the Romanized version. For example, \#432 遅 (245) displays the following readings: チ CHI, お く・れる oku(reru), おく・らす oku(rasu), おそ・い oso(i). Below all of this are example sentences and a list of compound words. To make identifying the kanji easier, the Romanized readings and English that represent the kanji character are underlined.

Japanese Language and Literature $\mid$ jll.pitt.edu

Vol. 54 | Number 1 | April 2020 | DOI: https://doi.org/10.5195/j1l.2020.147 
Just beneath the compound word list is a smaller area to practice writing. This often includes a small "writing hint," such as "Watch the stroke order一ユ,ノ, then 羊 (ひつじ)” for \#432 遅. Just below the hint is the number of strokes and a stroke order diagram, which shows a build-up of the character stroke by stroke. Finally, there is a writing practice grid, which contains eleven small boxes to practice writing. A half page of space is dedicated to each kanji character, its associated information, and writing practice. The presentation style is easy to follow and allows the user to find characters and pertinent information with ease.

After each set of kanji, which is approximately twelve kanji, are review exercises that typically include a variation of the following type of activities: (a) put words or small phrases written in kanji into their phonetic reading or vice versa, (b) translate English into Japanese by writing the appropriate mix of kanji and kana or vice versa and, (c) match words in kanji with the hiragana readings. After every three sets, which means thirty-six kanji, are review exercises that include a mix of the thirty-six kanji just covered as well as previously introduced kanji up to that point in the book.

$J K P$ has a few features that make it a standout, such as the etymology explanations, writing hints, and review exercises. The front matter contains clear descriptions of character components, radicals, and general stroke order rules. Keeping this information in mind, etymology explanations can help reinforce an understanding of the character's meaning. These explanations range from the simple, such as \#31 水 “The character 水 represents the current and ripples of a river," (17) to the more complex, such as \#432 遅:

The character 遅 originally consisted of movement 之, tail 尾 and cow 牛, referring to bovine animals $\mathrm{s}^{\mathrm{i}}$. Through phonetic borrowing the general meaning of slow movement has been adopted (245).

While the etymology notes for more complex characters like 遅 are interesting, it may not be effective to think of cows in order to associate this character with its meaning. However, such explanations do reinforce identifying a character's component parts and can help promote general awareness and interest in kanji. The author also notes in the front matter that not all etymology explanations are definitively accepted (vi), hence a few may have been the author's speculation.

The writing hints seem to be aimed at students who are already aware of some basic writing features. Common hints that are given include: "The \#th stroke protrudes" and "The \#th stroke tapers off." However, for

Japanese Language and Literature $\mid$ jll.pitt.edu

Vol. 54 | Number 1 | April 2020 | DOI: https://doi.org/10.5195/j11.2020.147 
students who may only have experience writing kanji in pencil or the average ballpoint pen, these hints may not be comprehensible. Furthermore, since the characters appear mostly in type font, some of these hints are not readily apparent by looking at the character. For example, \#342 決 says "The sixth stroke protrudes," (194) but for a learner of Japanese this may lead to confusion about how far it protrudes or what that stroke protrudes over. While the writing hints are appreciated, they will probably not be effective unless the users already have some understanding of what terms like "protrude" and "taper" mean.

Finally, the review exercises provide activities akin to what many native speakers use to study and review kanji, namely writing the readings of kanji and conversely writing kanji in the place of readings. While this may be effective for native speakers of Japanese, as a learner of Japanese one certainly needs more exposure (input) and writing opportunities (output) to remember the characters in context. The example sentences and review exercises, as well, often employ the casual form, or $d a / r u$ form, which may be more challenging for beginning students. Furthermore, while $J K P$ boasts that kanji are introduced in context, the only context provided is that inherent to the word, phrase, or sample sentence. Similarly, the majority of the review exercises center on only word-level or small phrase-level examples with no explanation of where one might see this word (e. g., in a newspaper article or in an informal email or text), which leaves it to the user to imagine in what real-world contexts you might find such words or how they are employed.

Finally, of particular note are the helpful reference numbers and acronyms for each character. The following acronyms are used in this order: JK for Joyyo kanji, GR\# to show the Japanese grade level, JLPT\# to represent to which level of JLPT the character belongs, and finally AP is included if the character appears on the Japanese AP exam. For example, \#31 水 has “GR1 JLPT 5 AP" (17), meaning it appears in Grade 1 of Japanese school, is on the JLPT 5 (and above), and is included in the AP exam. Noticeably, “JK" is missing from the acronyms even though 水 is one of the prescribed Joyo kanji. Oddly, most characters are missing the "JK" designation despite the fact that they belong to the Joyo kanji group. This is likely a small oversite by the author or editor, but it could lead to some confusion for students. However, the other acronym designations seem to be accurate and the feature allows users to tailor their studies to certain tasks. For example, if a learner used JKP in order to study for JLPT Level 3, they can easily identify kanji for JLPT as they worked their way through the book.

Japanese Language and Literature $\mid$ jll.pitt.edu

Vol. 54 | Number 1 | April 2020 | DOI: https://doi.org/10.5195/j1l.2020.147 
Where the book may lose a beginning or even intermediate level audience is in the examples and practice activities. Although the beginning characters may include what many consider to be basic kanji, this workbook includes many words considered atypical for a learner in beginning level Japanese. For example, within the common compounds for 水 is the word 水銀 suigin “mercury"; one of the example sentences is “水平線に夕日が沈むのを見た Suiheisen ni yūhi ga shizumu no o mita. 'I watched the sun set over the horizon"' (17). The level of difficulty in this and other sentences is beyond a beginner in Japanese language, but it does give a good representation of what is considered standard for a native learner. It is up to the user, then, to decide which words and examples to focus on. As beautiful as a sunset over the horizon may be, a language student will certainly find the word 水曜日 suiyōbi “Wednesday" more useful for everyday life and for lower to mid-range levels of the JLPT. Similarly, the review exercises are akin to what native speakers use to review kanji, but the level of vocabulary and lack of a larger context in which to apply the kanji make these activities more about memorizing pieces of vocabulary, which can be overwhelming.

Along with the aforementioned difficulties that learners may encounter using $J K P$, there are no examples of handwriting nor any audio materials to hear how the example words and sentences are pronounced. While each character is initially presented in brush type, how one writes a character can often differ from both brush type and computer font of the character. Any learner of Japanese has likely encountered the frustrating feeling when they receive a handwritten letter from a friend or host-family member only to find it indecipherable due to changes between type font studied in textbooks and handwriting style. Hence, examples of these characters in handwriting style would be a welcome addition. Finally, while $J K P$ focuses on reading and writing skills, learners of Japanese will certainly encounter a great deal of new vocabulary and sentences that they may want to apply in conversation. Without audio materials, however, users are forced to rely on their reading that could result in memorizing incorrect pronunciation or pitch.

$J K P$ is a useful workbook for any learner of Japanese but seems more appropriate for those who already have some background in the language or to adapt as a supplemental material. Those at the novice level will likely find the examples and amount of kanji in-between review exercises overwhelming. $J K P$ may be well suited to those wishing to review kanji and add from the intermediate level. The design and example sentences are similar to those in a dictionary and, for those at the intermediate level,

Japanese Language and Literature $\mid$ jll.pitt.edu

Vol. 54 | Number 1 | April 2020 | DOI: https://doi.org/10.5195/j11.2020.147 
they may find this similarity to what Japanese natives use to be enlightening and engaging. In particular, the etymology explanations provide insight into how kanji characters came to be and will likely motivate learners to enjoy kanji.

\section{NOTE}

${ }^{\mathrm{i}}$ In this example, the 尾 character is presented as 羊 with 尸 over it. Such a character does not exist in modern day Japanese, but is a more accurate depiction of how it appears in 遅. This could be advantageous for students to immediately see the component part being discussed, but at the same time may give the false impression of how tail is written today.

Japanese Language and Literature $\mid$ jll.pitt.edu 